\title{
The Dwelling Panel - A New Research Method for Studying Urban Change
}

\author{
Jürgen Friedrichs $\cdot$ Jörg Blasius
}

Received: 30 December 2014 / Accepted: 4 November 2015 / Published online: 20 November 2015

C Springer-Verlag Berlin Heidelberg 2015

\begin{abstract}
Classical panel studies, such as the German Socio-Economic Panel (GSOEP), the US Panel Study of Income Dynamics (PSID), and the British Household Panel Study (BHPS), are based either on households or persons in households. Any attempts to break down such data into smaller spatial units such as neighbourhoods, due migration and changes in a specific sample can only be described by the stayers and the out-movers. With the exception of new members in stayer households, there is no information on households moving into a given neighbourhood. Consequently, when using classical panel data, it is not possible to analyse appropriately changes in small areas.

In order to solve the problem of population changes in small spatial units such as neighbourhoods, we recommend using an alternative sampling unit: instead of households, we suggest focusing on dwellings and houses. The dwelling panel allows us to examine processes, such as gentrification, poverty and voting behaviour in small urban areas.

Drawing on an ongoing study, we shall discuss methodological issues and show how a dwelling panel can be constructed and maintained in several waves. In the process, we shall discuss panel attrition and compare possible replacement strategies in classical panels with those in dwelling panels.
\end{abstract}

\footnotetext{
J. Friedrichs $(\bowtie)$

Institute for Sociology and Social Psychology,

University of Cologne,

Greinstr. 2, Cologne 50939, Germany

e-mail: friedrichs@wiso.uni-koeln.de

\section{J. Blasius}

University of Bonn, Institute for Sociology and Political Science, Lennéstr. 27, D-53113 Bonn, Germany

e-mail: jblasius@uni-bonn.de
}

Keywords Dwelling · Panel study · Urban research · Neighbourhoods $\cdot$ Methodology $\cdot$ Cologne

\section{Das Wohnungs-Panel - Ein neues Verfahren zur Analyse von Stadtentwicklungen}

Zusammenfassung Klassische Panelstudien wie das deutsche Sozio-ökonomische Panel (SOEP), die US-amerikanische Panel Study Income Dynamics (PSID) und die British Household Panel Study (BHPS) haben als Zielpersonen Haushalte oder Personen in Haushalten. Ist man an kleinräumlichen Einheiten, z. B. Wohnvierteln, interessiert, können Veränderungen über die Zeit nur über die fortgezogenen und die verbliebenen Haushalte bzw. Personen beschrieben werden. Abgesehen von neuen Haushaltsmitgliedern, die in bestehende Haushalte einziehen, gibt es keine Information über diejenigen Haushalte, die in diese Wohnviertel einziehen. Wendet man klassische Panelstudien an, ist es daher nicht möglich, Veränderungen im Wohnviertel angemessen zu analysieren.

Um dieses Problem der Veränderungen in kleinräumlichen Einheiten zu beschreiben, schlagen wir als Alternative eine neue Untersuchungseinheit vor: anstelle von Haushalten die Wohnung (oder das Einfamilienhaus) zu verwenden. Das Wohnungspanel gestattet es, kleinräumliche städtische Prozesse zu untersuchen, z. B. Gentrification, Armut oder Wahlverhalten.

Am Beispiel einer laufenden Studie stellen wir die methodischen Annahmen dar und zeigen, wie ein Wohnungspanel konstruiert werden kann, das über mehrere Wellen läuft. Dabei diskutieren wir auch Panelausfälle und vergleichen mögliche Strategien, diese Ausfälle im klassischen und im Wohnungspanel zu ersetzen.

Schlüsselwörter Wohnungspanel · Panelstudie · Stadtforschung $\cdot$ Methodologie $\cdot$ Wohnviertel $\cdot$ Köln 


\section{Introduction}

Most urban researchers will agree that urban research is largely based on studies of processes, many of which were discussed by the Chicago school in the 1920s and 1930 . These include the socio-spatial integration of minorities, invasion-succession cycles, neighbourhood change, and suburbanization (Park/Burgess/McKenzie 1925; cf. the articles edited by Theodorson 1961; Theodorson 1982), which in the 1970s and 1980s was supplemented by gentrification (e.g. Clay 1979; Laska/Spain 1980; Smith/Williams 1986; and more recently Atkinson/Bridge 2005; Lees/ Slater/Wyly 2008; Lees/Slater/Wyly 2010; Brown-Saracino 2010).

Urban planning has, in the case of social mixes, also proposed measures such as a tenure mix to induce changes in neighbourhood composition and ameliorate the living conditions of poorer residents in deprived neighbourhoods (e.g., Galster 2008; Arthurson 2012; Manley/van Ham/Doherty 2012). The common element in this case is a change in the composition of neighbourhoods and - as a corollary - a change in the effect on neighbourhoods. In this case, the most striking examples of assumptions about changing neighbourhood effects are the North American experiments with poverty de-concentration, which involve the relocation of residents. See "Moving to Opportunity" (Orr/Feins/Jacob et al. 2003; Ludwig/Liebman/Kling et al. 2008; Briggs/ Popkin/Goering 2010; DeLuca/Duncan/Keels et al. 2012; Chetty/Hendren/Katz 2015), and "Housing Opportunities for People Everywhere (HOPE VI)" (Cisneros/Engdahl 2009; Popkin/Cunningham 2009; Fraser/DeFilippis/Bazuin 2012). ${ }^{1}$

We thus describe the opportunity structure, or the living conditions in a given neighbourhood, over time at the level of households and individuals, and not on the basis of aggregate data. In this respect, our main interest lies in urban dynamics. In other words: in processes. The study of such processes and structures usually requires panel data, i.e., data collected from the same units of analysis over time. When analysing the processes taking place within a certain neighbourhood, it is not enough to observe households or single persons as units over a certain time period. For if we take Cologne, for instance, approximately $13 \%$ of the residents move out of their dwellings each year on average

\footnotetext{
${ }^{1}$ Both MTO and HOPE VI are field experiments which relocate households from poor to less poor or non-poor neighbourhoods by random assignment. The aim of both panel studies was to explore the effects on households moving into better neighbourhoods with a variety of outcomes, e.g., employment, income, school achievement, etc. MTO (1994-2010) was composed of households in Baltimore, Boston, Chicago, Los Angeles and New York. HOPE VI (1992-2002) comprised grants from the US Department of Housing (HUD) to distressed areas in 165 cities.
}

(Stadt Köln 2012: 21, 38). Furthermore, these movements are highly dependent on age and owner-status. Studying migrants and conducting the next interview at a new residence - as in the case of panel studies such as the Panel Study of Income Dynamics (PSID), the British Household Panel Survey (BHPS) and the German Socio-Economic Panel (GSOEP) - is difficult due to the small numbers of migrants per neighbourhood and is, therefore, inadequate for describing changes at the neighbourhood level. We know the out-movers and the stayers, and we also gain information from the in-movers about persons entering a household through marriage, for instance, if the household is already included in the sample.

Neighbourhood changes can be studied with a variety of methods. These may comprise census tract data from cities or metropolitan areas, data from other small areas, such as the British Neighbourhood Statistics on wards, Layer Super Output Areas, ${ }^{2}$ and the Swedish SAMS data (e.g. Andersson/Musterd/Galster et al. 2007; Musterd/Galster/ Andersson 2012; Galster/Andersson/Musterd 2015). In the aforementioned cases, the bases of analyses are aggregated data and not single households or persons. Another disadvantage of census tracts is that they are usually formed by the surrounding streets. As a consequence, census tracts are often very heterogeneous. For example: one road happens to be one of the main streets in the city and has considerable 24-hour traffic, while another is a silent backstreet. It would be better to work with sections of streets containing houses that face opposite one another-but such data is, unfortunately, rarely available from statistical offices.

Secondly, cross-sectional population data can be used to study neighbourhoods or parts of cities. Typical studies contain descriptions of distressed neighbourhoods (e.g. Friedrichs/Galster/Musterd 2005) and neighbourhood network studies (e.g. Haynie 2001). The disadvantage of these studies is that they do not inform us adequately about sociospatial changes over time. Thirdly, this shortcoming is compensated for by panel surveys or series of surveys of the same residents, such as the PSID, the BHPS, the GSOEP and the HOPE VI Panel Study (e.g. Popkin/Cunningham 2009). Although these panels contain quite large samples, they seldom allow for analyses of single cities, and certainly not at the neighbourhood level, because the sample sizes within each sample point tend to be small. As a result, area effects can only be studied by aggregating sample points (with the drawback of adding heterogeneity). Furthermore, the sampling units in all these panels consist of households/ persons; in the case of out-migration, the panel will follow these people to their new address. As far as the (aggregated) area is concerned, we know who stays and who leaves, but we do not know who is replacing the out-moving house-

\footnotetext{
${ }^{2}$ See www.neighbourhood.statistics.gov.uk; retrieved April 2, 2015.
} 
hold/person in their former residence. In this case, the problem now becomes one of the insufficient inclusion of new households and exceedingly small samples in the sample units.

In general, all three research strategies (census, crosssectional and panel data) are valuable and have their merits, especially in terms of describing the attitudes and living conditions of persons/households at any one point in timeor several points in time - by conducting repeated crosssectional surveys, such as the bi-annual German ALLBUS. However, all these strategies are very limited for assessing processes in a given area or neighbourhood. They all address households or individuals in households over time adequately, but not the neighbourhoods themselves. Studying changes in a neighbourhood calls for a constant neighbourhood sample. Consequently, instead of following the out-movers, the latter have to be replaced by the respective in-movers. As a neighbourhood is composed of dwellings, it is the occupancy of these dwellings that needs to be examined in order to analyse changes in neighbourhoods: the succession of households in given dwellings or houses.

Therefore, we suggest changing the unit of analysis from the household to the dwelling or owner-occupied house. While the household can easily migrate, the dwelling/house can only be demolished or reconstructed - which seldom happens. And even if it could, it would simply be another indicator of urban change. With the dwelling panel, we have a replacement strategy that preserves the representative character of the area and allows us to study urban changes. Keeping the dwelling as the panel unit is a new research methodology that we shall discuss in this paper. ${ }^{3}$ As an empirical application, we shall use an ongoing panel survey in two neighbourhoods in the city of Cologne, Germany.

We shall first address the problems of panel studies and then move on to a detailed description of the dwelling panel construction. The next section focuses on the methodology and results of the Cologne Dwelling Panel. In the concluding section we shall summarize the advantages of dwelling panels and suggest further applications for urban research.

\section{Panel Studies}

In classical panel studies such as PSID, BHPS, and GSOEP, the samples are based on individuals or households. These panel studies collect information on a large set of variables and a large number of persons. For example, the PSID

\footnotetext{
${ }^{3}$ To the best of our knowledge, the only survey that comes closest to our dwelling panel is the New York City Housing and Vacancy Survey (NYCHVS). The survey is conducted every 3rd year and comprises 19,000 "housing units". But these are not fully identical in each wave; it is, therefore, not a panel in the strict sense (see www.census.gov/ housing/nychvs/; retrieved April 20, 2015).
}

started in 1968 with a nationally representative sample of over 18,000 individuals living in 5000 families in the United States. Since then information on these individuals and their descendants has been collected continuously, with the data covering socio-demographic characteristics such as employment, income, family status, and education, as well as numerous other topics. ${ }^{4}$

Panel data is partially suited for studying individual dynamics, such as individual changes in attitudes, education and incomes. Panel data facilitates causal interpretations, and also makes it possible to control for individual, unobserved heterogeneity (Heckman 1979; Hedman/van Ham 2011; Galster/Andersson/Musterd 2015).

In both the classical panel and the proposed dwelling panel, the steps taken to realize the first wave are the same: one must first choose a representative area, which depends, in turn, on the required sample size and the research project. This may be a single neighbourhood or a (large) number of neighbourhoods within a city or within a country. Secondly, representative samples in these areas must be chosen. In both the classical and the dwelling panel, the target persons in the first wave are either individuals or households. In the dwelling panel, a random sample of households will also result in a random sample of dwellings. From the second wave on, the methods differ in cases in which the target persons have migrated between the two waves: instead of following people that have migrated, we have now replaced the migrants by the new renters or the owners of the dwelling. In an additional survey, we could follow households that have migrated in order to retain the advantages of the classical panel. If the sample in the first wave is representative, and if we are able to replace the out-movers by the new residents, the second wave will remain representative of the area(s) of research. This, in turn, will enable us to study changes in the socio-economic composition of the neighbourhoods, the attitudes of their residents and their voting behaviour.

Dwelling panels, like all panel studies, are very dependent on the success of the first wave, and serve as a basis for all subsequent waves and analyses. The first problem is unit non-response. For example, the Swiss Household Panel started in 1999 with 14,174 household addresses, of which $12,084(=85 \%)$ could be contacted by telephone. Of these, $5074(=42 \%)$ ultimately participated in the survey. These 5074 households comprised 10,369 persons who were 14 years old or more (and therefore eligible to give an interview). From this sub-sample 7799 (or $75 \%$ ) gave an interview (Budowski/Tillmann/Zimmermann et al. 2001: $118-119)$. One common solution to solving this problem is to weigh data, although this, too, creates problems (Spiess 2005; Brick 2013).

\footnotetext{
${ }^{4}$ See http://psidonline.isr.umich.edu/; retrieved March 10, 2015.
} 
The second problem is out-migration. In large nationwide panels this issue is usually solved by following the households that have moved out, and, if possible, by conducting interviews at their new addresses. In face-to-face surveys, the costs of conducting the interviews rise with each successive wave, since the physical distances between the households also increase. In the dwelling panel, the unit of analysis is the dwelling; it is, therefore, essential to interview the household which is the new renter (owner) of the dwelling. If one is aware of the exact position of the dwelling within a building, it is possible to identify the name of the new resident and ask for an interview with a randomly selected adult person in the new household. Not only that, we can conduct an interview with out-migrants (e.g. by mails or phone-calls to reduce costs) by tracing the new household address. In this way, it is possible to combine the classical panel with the dwelling panel in order to exploit the advantages of both methods.

The third problem is panel attrition arising from refusals as a result of lack of further interest, health problems or other reasons. The greatest number of losses occurring for these reasons take place between the first and the second wave: In the PSID and the BHPS, attrition rates between the first and the second wave were $12 \%$, while in the following waves they were between 3 and 5\% (Fitzgerald/Gottschalk/Moffitt 1998: 254; Burton/Heather/Lynn 2006). To compensate for panel attrition, several replacement procedures have been suggested, generally by adding new units (persons, households) to compensate for the losses (Hagenaars 1990: 249-263; Vermunt 1996; Frees 2004: 263; Lynn 2009). The replacement strategy in dwelling panels is more advantageous than in the case of classical panels: instead of searching for persons (or households) comparable to the lost cases, it is necessary to search for dwellings comparable to those that have been lost. In classical panel studies, the refusals are replaced by randomly selected persons or households, e.g. from the same sampling unit but at random - and as a new case. The characteristics of new dwellings, in contrast, are relatively well known, at least the price of the dwelling (or the rent) is a known factor. Furthermore, the area is familiar (as are the prices and the living conditions in the area), and the size of the new dwelling is easy to estimate (or known). In addition, the exact location within the neighbourhood is known. In summary, the replacements in a classical panel may ensure that the panel in its entirety retains its representative character. This is not the case with regard to a single neighbourhood, however, as it would be with a dwelling panel.

Dwelling panels may suffer from a fourth problem: the destruction of a building. If no new buildings have been constructed on the same site, it will be impossible to replace the lost dwellings. If a new residential building is constructed, it will be worth trying to obtain interviews from the same number of households as existed in the initial build- ing. Another problem might occur when two (or even more) dwellings are combined to create one. If only one of the former dwellings is a panel member, the dwelling will remain in the panel and we will obtain data on both the changes in the characteristics of the dwelling and the changes in the renter or owner. In any event, the destruction of buildings and/or construction of new buildings is also an important indicator for describing urban processes.

Fifth, one of the disadvantages of classical panel data is that it loses its representative character after the first wave, even in a random case of panel mortality. This is relatively easy to explain. Assuming that the time difference between two waves is 1 year, and that at $t 1$, a point in time, the average age prevails $\bar{x}$, corresponding to the average age of the target population. At $t 2$ the average age of the panel members is $\bar{x}+1$, while the average age of the population remains the same as it was the year before. In large household panels such as the PSID, this problem will be more or less solved at the national level by including the household members in a panel whose age exceeds a certain threshold. In single neighbourhoods, however, this replacement is unlikely to be random. In dwelling panels, it is the dwelling that is considered representative.

Sixth, another serious problem is caused by out-migration. Since younger people migrate more frequently than older people, the stayers are generally older than the out-movers. Consequently, without following the migrants, the age difference between two waves will be even greater than $\bar{x}+1$. Both problems are well known, and many solutions have been proposed in the pertinent literature on how to compensate for panel attrition and how to handle the increasing age of the panel members (e.g. contributions in Lynn 2009). In the dwelling panel the out-movers are replaced by the in-movers, and an increase (or decrease) in age can be interpreted as neighbourhood change, since neither the increase in age of the stayers nor the varying socio-demographic characteristics of the out-migrants has any effect on the representative character of the data. Note that the target population might differ somewhat: In the classical nationwide panel it is the entire population; in a nationwide dwelling panel it is the population in the selected areas.

In the case of dwelling panels, one must distinguish between replacement cases in the form of (a) houses and (b) dwellings in multi-family buildings. In the case of houses, one has an opportunity to choose the house closest to that of the dweller who has left the panel; alternatively, one could apply special criteria such as the neighbour's house on the left (or right). Another option would be to choose a house nearby that is most similar in terms of size, age and (estimated) value, as this might be the best way of preserving representativeness. In multi-family houses one might chose a dwelling that is located opposite the initial one or lies exactly at the same position in the building — but one floor 
above (or below). If this household refuses to participate, one can then contact the next household. As in the case of the classical panel, it is of utmost importance to adhere to a strict model of how to select the new households in a way that preserves a random sample.

The dwelling panel refers to dwellings. Each year, a certain large number of the households (between 10 or $15 \%$ of the households) of renters rather than owners (Galster 1987; Friedrichs/Blasius 2009) moves to a new residential location. The dwellings remain the same, however, and emerging changes in their features may be reported. In the case of gentrification, changes may be observed e.g. from households with children towards households without children, rent increases of $25 \%$ or more above the city average, or the conversion of rented dwellings into a condominium. If poverty is rising in the neighbourhood (Wilson 1987; Sampson 2012), this may result in a noticeable change from young and well-paid single- or dual-earner-families to families living on social assistance or unemployment benefits. At the same time, investments in dwellings tend to decrease and perhaps generate a greater degree of disorder in a given neighbourhood (Skogan 1990). As far as voting behaviour is concerned, one can identify changes in party preferences among the electorate. Spatial cleavages may change if outmoving Social-Democratic voters are replaced by in-moving Christian-Democrats, or Liberals.

Another theoretical alternative to the dwelling panel is that of cross-sectional data, for example, which involves collecting repeated random samples over a period of time from the same target population or the same neighbourhood. This kind of data does not provide information on changes at the micro-level, however. A variety of causal interpretations will only arise if panel and/or experimental data is used, since the diversity of cross-sectional data is very limited.

\section{Dwelling Panel Construction}

\subsection{Data Structure}

Dwelling panels, like classical panels, also make it possible to draw random samples of persons or households and to collect data from all members of a community above a certain age threshold. Dwelling panels, in contrast, offer more complex data structures than classical panels. First, dwelling panels consist of data from target persons (households) who have remained in the sampled dwellings over the entire period; for these stayers, there is no difference between the classical and the dwelling panel. Second, changes in household composition may occur: (a) the target person has left the dwelling, (b) a member of the household has left the common dwelling, or (c) a person has moved into an already existing household. In case (a) the target person has to be replaced by another member of the household, which in turn may be correlated with a change in the socio-demographic characteristics and attitudes; in cases (b) and (c) the household composition has changed, which might as well result in changes in attitudes (for example, after a divorce) and household characteristics, such as income, for instance. Third, households move out and new households move in - this occurs between two successive waves. Fourth, in cases in which households have remained in their dwelling but refused to take part in a further wave, information is still available about the target dwelling; as it is well-known that there is no migration, information (such as income, rent for the dwelling, size of the dwelling, and household composition) can be kept from the previous wave as a proxy measure.

Let us take the example of the dwelling panel and assume that there are two dwellings $\mathrm{X}$ and $\mathrm{Y}$, which are sample units in the data set (Table 1). At time $t 1$, when the first wave of interviews is conducted, dwelling $\mathrm{X}$ is rented by household A. Between $t 1$ and $t 2$, the date of the second wave, nothing changes in this dwelling, renter A remains there. Before the next wave occurs at time $t 3$, renter A moves out and renter $\mathrm{B}$ moves in. In the most favourable case, renter $\mathrm{B}$ agrees to participate in the survey and replaces renter A in the dwelling panel. Not only that; the former renter A can be asked to participate again, as is the case in classical panel surveys. Between waves $t 3$ and $t 4$, renter B has left dwelling $\mathrm{X}$ and renter $\mathrm{C}$ moves in. When it comes to wave four, dwelling $\mathrm{X}$ has had three different renters (A, B, and C): Renter A, who has been participating since the first wave, renter B, who has been participating since the third wave, and renter $\mathrm{C}$, who entered the panel during the last wave. In contrast, there is no change in dwelling $\mathrm{Y}$, and renter D stays in the same dwelling all the time. This sample unit is reminiscent of the classical panel study.

As already mentioned, the data structure of the dwelling panel is somewhat more complex in comparison with classical panel studies, since it includes changes in households and target persons. With migration, some explanatory variables that are usually treated as constant may change between two waves. For example, the gender composition of a household may change, and the highest educational

Table 1 Data structure of a dwelling panel (upper part) and a classical panel (lower part)

\begin{tabular}{lllll}
\hline Target object & $t 1$ & $t 2$ & $t 3$ & $t 4$ \\
\hline Dwelling X & Renter A & Renter A & Renter B & Renter C \\
\hline Dwelling Y & Renter D & Renter D & Renter D & Renter D \\
\hline Renter A & $\mathrm{x}$ & $\mathrm{x}$ & $(\mathrm{x})$ & $(\mathrm{x})$ \\
Renter B & & & $\mathrm{x}$ & $(\mathrm{x})$ \\
Renter C & & & & $\mathrm{x}$ \\
Renter D & $\mathrm{x}$ & $\mathrm{x}$ & $\mathrm{x}$ & $\mathrm{x}$ \\
\hline
\end{tabular}

(x) to be asked only in case of combining the dwelling panel with the classical panel 
level may also decrease between two waves. The sum of these changes within the neighbourhood may help analysts in studying urban processes, such as incumbent upgrading, gentrification, poverty, and changes in the electorate.

Finally, changes in the dwelling can be studied. For example, a rent increase might distinctly exceed the inflation rate, and the building might undergo a certain degree of modernisation in which two or more dwellings are combined to create a single one.

\subsection{Panel Construction}

The dwelling panel starts spatially. In this case, the sample unit is a dwelling or house-either rented or owned. The first wave in dwelling panels is the same as in classical panels, where the data are collected face-to-face. For a given area-which might be a neighbourhood or a (large) number of neighbourhoods - a random sample of households (or persons in households) is drawn from the population register.

A crucial problem with a dwelling panel is how to identify the dwellings in a multi-family house. This is a prerequisite for identifying dwellings from which the target persons have moved out. It is obvious that when a first interview is conducted, the dwellings' exact positions have to be recorded. We suggest two methods: a stair walk - the most general solution - and the bell-board, which has the advantage of being applicable to most European cities.

The interviewer, who has the addresses of the interviewees (city, street and number of the multi-family house), begins the stair-walk method on the ground floor and assigns the first dwelling to the left 1_1, the second one to the left $1 \_2$, and so on. When two households only are on the same floor, 1_2 is the first floor to the right; with $k$ households on the same floor, the first household to the right is $1 \_k$. The person reporting the exact location of a dwelling in a multifamily house then walks up the stairs and assigns 2_1 to the first dwelling to the left, $2 k^{*}$ to the right dwelling (note that $k$ and $k^{*}$ can be different), and then proceeds to the next higher storey and continues counting in this manner. This method ought to be applicable to almost all residential buildings; the exact locations of the dwellings can be noted during the first wave.

A more specific method involves identifying dwellings by the bell-board. In most European cities a bell-board is attached, or moulded, to the wall next to the entrance of multi-family buildings. The bell-board lists the names of renters (owners) and a bell-button is attached to each name. ${ }^{5}$ A typical type of bell-board is shown in Fig. 1a. It refers to a multi-family building with two dwellings on each of the

\footnotetext{
${ }^{5}$ In case of sub-renters not listed on the bell-board, they cannot be identified in the first wave-unless s/he is in the random sample.
}

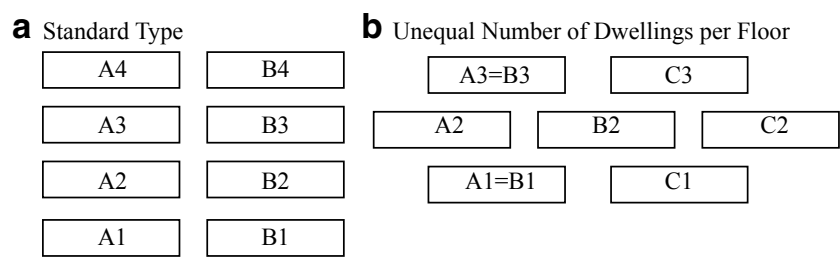

Fig. 1 Bell-board on interviewer's contact sheet

four floors (if there were three households on the floor, a third column would have to be added). To identify the locations of the dwellings with an unequal number of dwellings per floor, a different bell-board layout is needed, as shown in Fig. 1b, for instance.

When undertaking field work, we suggest the following approach: When the interviewers conduct the first wave, they are equipped with a contact sheet for each respondent, which lists the name of the target person, the name of the street, and the house number where s/he lives. In addition, $\mathrm{s} /$ he has a simplified version of the contact sheet as shown in Fig. 1a, where s/he can identify the bell-board location; further rows and columns can easily be added. If the interviewer encounters a special type of bell-board (as shown in Fig. 1b) this has to be noted in the contact sheet, by doing a new drawing, for example. To confirm that all interviewers have taken sufficient note of their instructions (which cannot be assumed, since some interviewers take short-cuts when conducting their interviews; cf. Blasius/Thiessen 2013), we recommend sending a project assistant or, in general, a trusted person, to check the allocations of the names to the bell-board locations by the end of the first wave at the latest.

After the interviews of the first wave have been completed, a list of all the participants and their addresses should be made - comprising as well the locations of the related dwellings. Note, that the dwelling panel works only if all locations of all dwellings and all the houses can be reproduced without errors.

The second wave, and all of the successive waves, begin with personalized letters, which call for further participation and perhaps for further incentives, too. This aspect of panel maintenance is the same as that used in classical panel studies; in this case, we refer to the pertinent textbooks (Hagenaars 1990; Finkel 1995; Frees 2004). In cases in which the household has migrated, the invitation letters will be returned to the respective research facility within a few days. Since it normally will be unknown who moved into the new dwelling, somebody will have to check-up on the new name, which is displayed either on the bell-board or by stair walk. Problems may occur where the target household has just moved out without a new household moving in during the field period. In these cases interviews cannot be conducted: "the dwelling is not available". The same holds true for dwellings that have remained uninhabited for 
a longer period, which may be due to extensive renovation, or to a rental fee that is too high for the local market. This information is also important not only for describing urban processes, but also for subsequent waves during which the dwellings might accommodate residents.

\subsection{Questionnaire}

One main advantage of dwelling panels is the spatial context and the opportunity for studying changes in the neighbourhood(s) without losing representativeness. In addition to questions that are necessary for describing spatial changes, there may be other questions requiring consideration that will depend on the specific research purpose. We suggest distinguishing between core and supplementary modules. The core modules might comprise the following dimensions and corresponding variables:

1. Household data: e.g. the number of persons living in the household, the age of the individual household members, the income of all household members, and the educational level of all household members. (This data will also be collected for classical panel surveys.) Furthermore, in dwelling panels we recommend checking the move-in date for this dwelling, the prior location (last place of residence), and any possible intention to move out. All this data can be collected at the individual level and assigned to the dwellings.

2. Dwelling data: e.g. size (measured in square meters), the number of rooms, equipment (number of baths, toilets, kind of heating system), the amount of rent, and the tenure status (social housing, private renter, owner). In most cases there will probably be no change in size or the number of rooms. If there will be a noticeable upgrading of the equipment, a large increase in the rent and/or a change in the tenure status towards ownership, this might be indicators of gentrification. No increase in the rent over a long period and no changes in the equipment of the dwelling may be indicators of downgrading. The status of some of these indicators will remain the same in subsequent waves and can easily be used in case of refusals; the other ones might probably serve as proxies.

3. Building data: e.g. location in city, age (year of construction), condition (modernisation, façade), single vs. multiple uses: only residential vs. residential plus offices/ shops, number of dwellings, energy efficiency (if available). While the first two indicators remain constant over time, the others will serve as indicators of possible up- or downgrading. This information also is available in case of refusals.

4. Regional data: e.g. GNP, the percentage unemployed, percentage of foreign-born, migration statistics (inmoves, out-moves).
5. Observational data: The interviewer rates the condition of the dwelling on five-point scales. For example: cleanliness, the kind of furniture, and the condition of the walls/wallpaper. Since the dwelling is the sample unit, changes in the observational data can be interpreted as being equivalent to changes in the social status and income dynamics.

It is evident that other modules can be added on the topic of interest; for example, satisfaction with the dwelling and the neighbourhood, perceived changes in the neighbourhood and lifestyles. Other modules may refer to party preferences, work, ego-centred networks, or attitudes towards, and contact with, ethnic minorities, including intra-ethnic contacts.

Data for parts one to three can presumably be supplied by any adult in the household. Data for the fourth section may well be assembled by the researcher; data for the fifth section depends on the individual person of the household answering the questions.

\section{An Example: The Cologne Dwelling Panel}

We asked the Cologne Office of Statistics and Population to draw a random sample in two pre-selected neighbourhoods of persons aged 18 years and older in Cologne, Germany. Both areas are on the right side of the river Rhine: (a) Mülheim, neighbouring at the north of (b) Deutz. After the streets (or parts of them) had been selected, the Cologne Office of Statistics and Population provided us with a random sample of $N=2372$ addresses. Using these, we sent out individual letters to the target persons in which we briefly explained the aim of our research and informed them that an interviewer would contact them within the next days. Since our budget was limited we decided for a random sample of persons that is representative of the entire neighbourhood. However, this included the over-sampling of larger households; and for some analyses of neighbourhood changes we had to weight the data.

To achieve a high response rate, all interviewers underwent a detailed introduction to the questionnaire and were provided with an identity card with a photo and the University logo. Furthermore, all interviewees were informed about the interview and the purpose of the study (living conditions in their neighbourhood) by personalized advance letter. Fieldwork of the first panel wave took place in the summer of 2010, the second wave in autumn 2011. Interviewers had to fill in a contact sheet for each address and had to contact the target person up to 10 attempts. If the target person was not reached at the end of the field phase, those addresses were contacted again by two of the most experienced interviewers. 
At the end of the first wave fieldwork, we obtained a sample of $N=1009$ respondents for the two residential areas, with $N_{1}=602$ in Cologne-Deutz and $N_{2}=407$ in CologneMülheim. The second wave was conducted approximately 15 months later, here we performed 878 interviews in total, with $97(=11 \%)$ replaced respondents.

Table 2 shows samples and numbers of completed interviews in both waves. The rate of $45.7 \%$ of completed interviews in a face-to-face study in the first wave is quite satisfactory, since even larger and well-known surveys, such as the bi-annual (German) General Social Survey (ALLBUS), had a response rate of $40.8 \%$ in Western Germany and $39.8 \%$ in Eastern Germany in 2008 (Wasmer/Scholz/ Blohm 2010: 55).

In the second wave, we subdivided the sample into stayers and replacements. As Table 2 shows that, as far as the stayers are concerned, we had convinced $88.0 \%$ of all of the panel members to participate a second time round. The rather high rate of panel members that were unavailable also results from the fact that it usually takes a few weeks for one household to leave its dwelling and a new one to move in - and, of course, just prior to and after migration hardly anybody has time for an interview. Furthermore, as already explained, we do have information from those 107 panel members who - during wave two - either refused to participate or were not at home during the field period. 51 persons who were "not at home" included those who had moved out in this period and had not been replaced in the meantime.

It is important for the success of the dwelling panel to get hold of the interviews from the 121 persons who moved into the panel via migration. Since we only had the new names from the bell-boards (without knowing the household composition) and since we tried to collect as many interviews as possible, we left it to the respective households to decide

Table 2 Samples and completed interviews

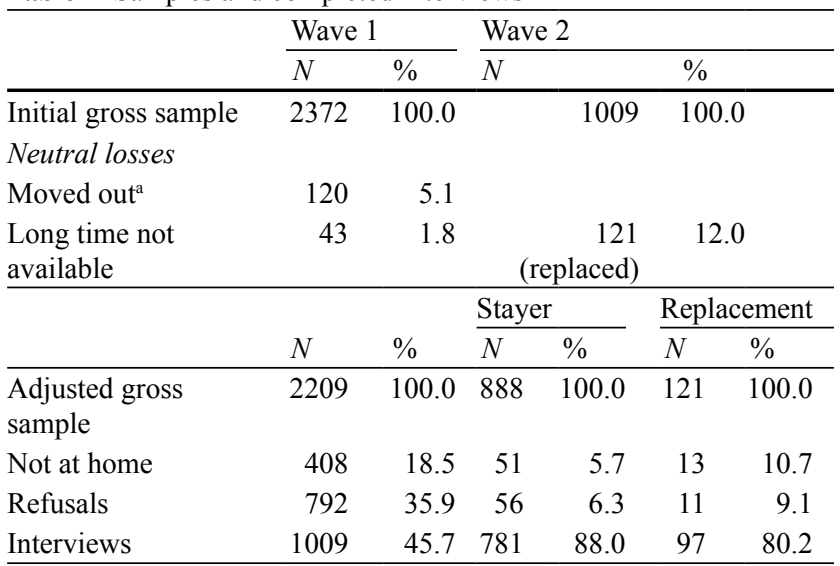

${ }^{a}$ Moved out before start of the field phase; presumably some even in the Population Register sample although already moved out who should take part in the interview. ${ }^{6}$ From the 121 new target persons we were able to conduct $97(=80.2 \%)$ interviews, which is a very good value.

Another important issue (not reported in Table 2) is that, of the 888 stayers, 25 persons who were interviewed in the first wave $(=2.8 \%)$ moved out and had to be replaced by a new target person from the same household. As in the case of replacement-and for the same reasons-we left it up the household to decide who should become the new target person; this was successful in 24 cases $(=96.0 \%)$, only one household refused to participate - and from this household we were still able to gain some information. If we perpetuate the information of the stayers who refused, or were not at home during wave two, we still have information from the 107 respondents who participated in the first wave. Compiling all of the information for analyses, we have been able to use the information from 985 respondents $(=97.6 \%)$, and have acquired complete information from 878 respondents $(=87.0 \%)$. In a classical panel on persons (without following the migrants), we would have only 757 (=75.0\%). Figure 2 provides a graphical overview.

At wave 3, the target dwellings are the same as above, i.e. the target sample remains constant. It will consist of the 888 stayers and 121 replaced households from the second wave, in other words, the 1009 dwellings from wave 1 in total. Once again, there will be out-movers that will have to be replaced by the new residents using the bell-board method and, in addition, persons moving out of the household who have to be replaced by another member of the same household.

To provide an example of the advantages of the dwelling panel, we shall show a map that includes all of the participants in wave one in the second wave (Fig. 3). In this case, the dwelling panel members were divided into (a) 757 dwellings in which the target persons could be interviewed a second time (shown by a solid circle), (b) 24 dwellings with a change in the target person, but still in the same household (solid star), (c) 107 dwellings in which the target persons refused to participate a second time, or where they were not at home (empty circle with dot), (d) 97 dwellings with new

\footnotetext{
${ }^{6}$ We discussed applying the next (last) birthday method as proposed in AAPOR (2007). However, we are aware that this instruction is hard to implement for an interviewer; furthermore, in face-to-face interviews it is almost impossible to establish whether the interviewers have complied with this instruction. In Germany, at least, the date of birth is considered sensitive information related to data security issues and people will not necessarily understand what this information is for. To start with, this question would increase the number of refusals, either because people simply do not want to answer certain questions and therefore refuse to participate, or because the eligible person is not at home at the time of contact. Furthermore, many interviewees who had participated refused to answer control questions of this nature on the telephone to an anonymous person from an institute, and finally, there might be a change in the "next birthday" in the time period between the interview and the control call (cf. Blasius/Thiessen 2013).
} 


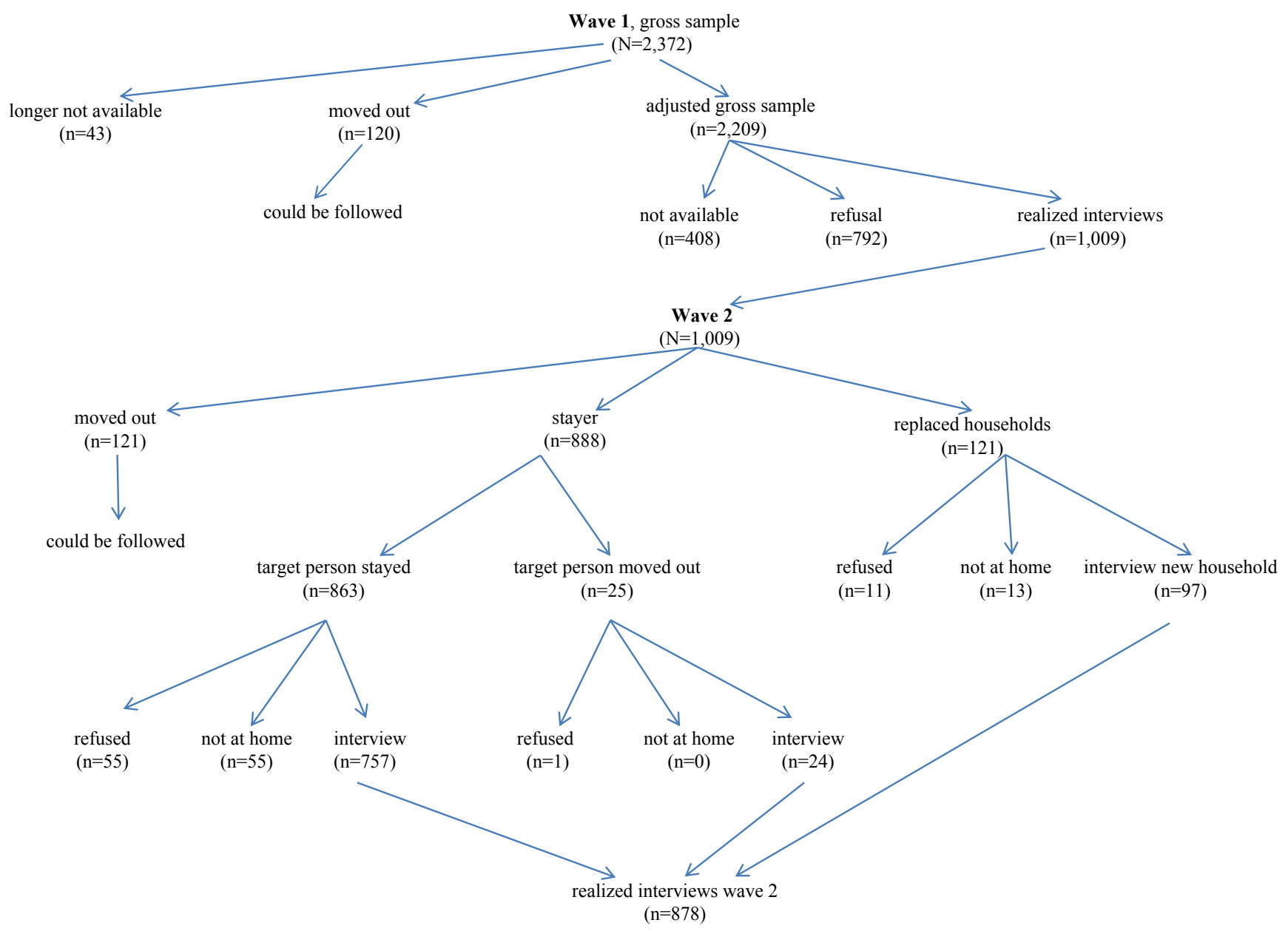

Fig. 2 The Cologne dwelling panel: Structure of the first two waves

households who participated (solid diamond), and (e) 24 dwellings in which the new residents either refused to participate or where they were not at home (empty diamond).

As Fig. 3 shows, the households that we would lose in a classical panel are not at all equally distributed along the entire sample area: they are, in fact, concentrated in certain neighbourhoods. Furthermore, in some neighbourhoods there are almost no changes, the households remained and participated in both waves, while other parts of the neighbourhoods are characterized by a comparatively higher rate of migration. After conducting several waves the pattern of migration and their spatial impacts can be interpreted in more detail.

\section{Conclusions}

From our point of view, a dwelling panel is the best methodological approach to study urban change over time. Instead of following migrants, which becomes expensive with face-to-face interviews, the new resident is interviewed.
And since the dwelling is the sample unit, even in case of refusals and "not at home", there is still some information available on the dwellings and their residents. For instance, household composition and dwelling characteristics can be assumed to remain unchanged over a period of 2 , or maybe 3 , years. Based on the Cologne dwelling panel, we outlined the construction of a dwelling panel of this nature. More generally, dwelling panels have several advantages.

First, it allows for studying changes in the urban structure of greater detail than is the case in classical panel studies, since it does not lose its representative character for the neighbourhood(s) over time. If, for instance, a household has been interviewed in two consecutive waves, but refuses a third time, this allows it to replace a number of missing values by those previously observed. This might be a more valid method than that of replacing missing values with the mean.

Second, with a large sample in the neighbourhood, one can answer questions such as: Does gentrification occur in the sampled area(s)? Is the rate at which a given poverty area becomes poorer, rather like other areas in the city? 
Fig. 3 Participants in first and second wave

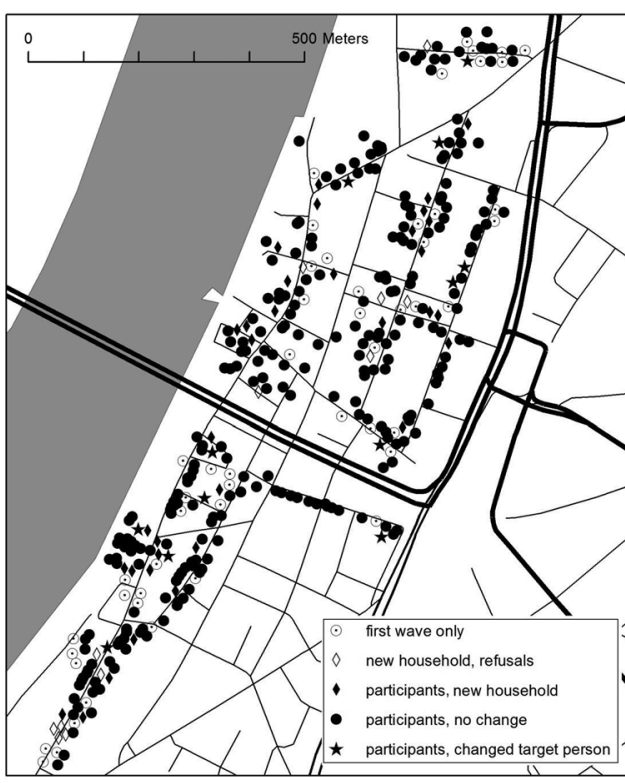

Cologne - Mülheim

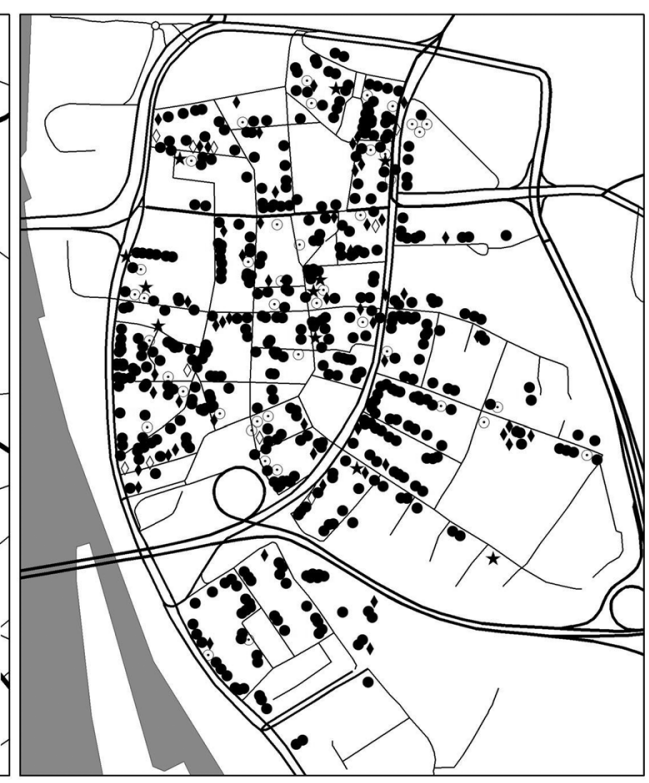

Cologne - Deutz
Has the social mix increased or decreased? Which household changes are responsible for changes in voting patterns? And, more generally: Does the altered neighbourhood composition have any other impacts on the residents (neighbourhood effects) in comparison with the initial composition?

Third, we can assess changes such as composition by household size, by social status, and by ethnicity. Furthermore, we can examine changes in social capital, attitudes, and conflicts. We may even study the history of single dwellings.

Fourth, Schelling's model of social segregation (Schelling 1971; Schelling 1978) can be tested with empirical data. ${ }^{7}$ The dwelling panel allows for perfect measurement of the assumed transition from heterogeneity to segregation.

Fifth, dwelling panel studies do not have to rely upon administrative spatial units such as wards or census tracts. Neighbourhoods can be aggregated from the dwellings to create different sizes. Thus, dwelling panel studies can become an important instrument for monitoring changes and guiding urban planning.

Sixth, a further advantage of dwelling panels is that they allow us to study changes in the electorate over time. As early as 1944, Lazarsfeld/Berelson/Gaudet showed that party preferences are related to social class, religion and urban-rural residence. Since then there has been ongoing research in this area. In many studies a spatial unit, the electorate, has been used to add macro information in order to

\footnotetext{
${ }^{7}$ The Schelling model simulates spatial segregation processes. It consists of a checkerboard with, for instance, 35 white and 20 black households randomly distributed over the 64 squares. By setting preferences for both groups on the number of households with the same ethnicity they desire as neighbours (adjacent squares), households are moved on the checkerboard, which results in an unanticipatedly high spatial segregation among both groups.
}

explain voting behaviour. It is in this way that changes are usually described at the macro-level in American studies, as is the case, for instance, in the Voter Tabulation Districts (VTD). According to Myers (2013: 49) "VTDs are arguably the best aggregate units available for examining geographical differences in American voting behavior". However, these data are taken at the aggregate level; they do not contain individual level information.

With the dwelling panel, the data can be used to study shifts in a partisan change in a small field such as an electorate (or a part of it). In contrast to macro level data, the dwelling panel makes it possible to distinguish between (a) changes in the micro motives of the people staying over time in the area that might cause changes in their voting behaviour, and (b) changes in voting caused by the in- and out movement of residents. Furthermore, since the changes can be documented at the micro level, they can also be analysed by controlling for other important variables affecting voting behaviour, such as religion and social class.

Finally, by comparing the households that moved out of the neighbourhood to those that have stayed and to those who have moved in, we can examine the changing composition of households in the neighbourhood. In addition, we can document changes in the attitudes and lifestyles in a given neighbourhood - a major proposition of gentrification theory (Lees/Slater/Wyly 2010). In other words, we are thus able to examine a genuine gentrification process due to new residents (households) contrasting the results with changes that might have occurred as well if the old households had stayed in their dwellings. In election studies, one can examine changes in the electorate: the in-movers may change the existing milieu in a neighbourhood or constituency, respectively. 
Tracing the migrants and conducting the next interview at their new residence (as it is done in panel studies such as the PSID, BHPS or the GSOEP) will not suffice to describe changes in a neighbourhood, since the out-movers no longer live in the neighbourhood of interest, and with the remaining persons (households) the area ceases their representative character in the long run. Whereas the household can easily migrate, the dwelling/house can only be demolished or reconstructed. Classical panel studies follow human beings; they are the focus of interest. Dwelling panels are centered on the dwellings: neighbourhoods are the focus of interest. In the case of nationwide panels, it remains an empirical question, with regard to the superior strategy, i.e. of tracing people/households with all the problems that tracing them entails, by following migration (and maybe their children, as a strategy for keeping the sample representative over time) or tracing their dwellings under the assumption that the selected sample points retain their representativeness for the entire country: we clearly favour the latter alternative.

Funding Research was funded by the German Science Foundation, grants Fr 517-28/1, 2.

\section{References}

AAPOR (American Association of Public Opinion Research) (2007): Why Sampling Works. www.aapor.org/Why_Sampling_Works1. htm. (Accessed February 23, 2013).

Andersson, R.; Musterd, G.; Galster, G. C.; Kauppinen, T. (2007): What Mix Matters? Exploring the Relationships between Individuals' Incomes and Different Measures of Their Neighbourhood Context. In: Housing Studies 22, 5, 637-660.

Arthurson, K. (2012): Social Mix and the City. Collingwood.

Atkinson, R.; Bridge, G. (eds.) (2005): Gentrification in a Global Context. The New Urban Colonialism. London.

Blasius, J.; Thiessen, V. (2013): Detecting poorly conducted interviews. In: Winker, P.; Menold, N.; Porst, R. (eds.): Interviewers' Deviations in Surveys - Impact, Reasons, Detection and Prevention. Frankfurt am Main, 67-88. = Schriften zur empirischen Wirtschaftsforschung, 22.

Brick, J. M. (2013): Unit Nonresponse and Weighting Adjustments: A Critical Review. In: Journal of Official Statistics 29, 3, 329-353.

Briggs de Souza, X.; Popkin, S. J.; Goering, J. (eds.) (2010): Moving to Opportunity. The Story of an American Experiment to Fight Ghetto Poverty. Oxford.

Brown-Saracino, J. (2010): The Gentrification Debates. London.

Budowski, M.; Tillmann, R.; Zimmermann, E.; Wernli, B.; Scherpenzeel, A.; Gabadinho, A. (2001): The Swiss Household Panel 1999-2003: Data for Research on micro-social Change. In: ZUMA-Nachrichten 49, 100-125.

Burton, J. L.; Heather, L.; Lynn, P. (2006): The Long-term Effectiveness of Refusal Conversation Procedures on Longitudinal Surveys. In: Journal of the Royal Statistical Association 169, 3, 459-478.

Chetty, R.; Hendren, N.; Katz, L. F. (2015): The effects of exposure to better neighborhoods on children: New evidence from the Moving to Opportunity experiment. Cambridge. $=$ National Bureau of Economic Research (NBER) Working Paper 21156.
Cisneros, H. G.; Engdahl, L. (eds.) (2009): From Despair to HOPE. HOPE VI and the New Promise of Public Housing in America's Cities. Washington.

Clay, P. L. (1979): Neighbourhood Renewal. Middle-class Resettlement and Incumbent Upgrading in American Neighbourhood. Lexington.

DeLuca, S.; Duncan, G. J.; Keels, M.; Mendenhal, R. (2012): The Notable and the Null: Using Mixed Methods to Understand the Diverse Impacts of Residential Mobility Programs. In: Van Ham, M.; Manley, D.; Bailey, N.; Simpson, L.; MacIennan, D. (eds.): Neighbourhood Effects Research: New Perspectives. Dordrecht, 195-224.

Finkel, S. E. (1995): Causal Analysis with Panel Data. Newbury Park.

Fitzgerald, J.; Gottschalk, P.; Moffitt, R. (1998): An Analysis of Sample Attrition in Panel Data: The Michigan Panel Study of Income Dynamics. In: Journal of Human Resources 33, 2, 251-299.

Fraser, J.; DeFilippis, J.; Bazuin, J. (2012): HOPE VI: Calling for Modesty in its Claims. In: Bridge, G.; Butler, T.; Lees, L. (eds.): Mixed Communities. Gentrification by Stealth? Bristol, 209-229.

Frees, E. W. (2004): Longitudinal and Panel Data. Cambridge.

Friedrichs, J.; Blasius, J. (2009): Attitudes of Owners and Renters in a Deprived Neighbourhood. In: European Journal of Housing Policy 9, 4, 435-455.

Friedrichs, J.; Galster, G. C.; Musterd, S. (eds.) (2005): Life in Poverty Neighbourhoods. European and American Perspectives. London, New York.

Galster, G. C. (1987): Homeowners and Neighborhood Reinvestment. Durham, London.

Galster, G. C. (2008): Quantifying the Effect of Neighbourhood on Individuals: Challenges, Alternative Approaches and Promising Direction. In: Schmollers Jahrbuch 128, 1, 7-48.

Galster, G. C.; Andersson, R.; Musterd, S. (2015): Are Males' Incomes Influenced by the Income Mix of their Male Neighbors? Explorations into Nonlinear and Threshold Effects in Stockholm. In: Housing Studies 30, 2, 315-343.

Hagenaars, J. A. (1990): Categorical Longitudinal Data. Newbury Park.

Haynie, D. L. (2001): Delinquent Peers Revisited: Does Network Structure Matter? In: American Journal of Sociology 106, 4, $1013-1057$.

Heckman, J. J. (1979): Sample Selection Bias as a Specification Error. In: Econometrica 47, 1, 151-161.

Hedman, L.; van Ham, M. (2011): Understanding Neighbourhood Effects: Selection Bias and Residential Mobility. In: Van Ham, M.; Manley, D.; Bailey, N.; Simpson, L.; MacIennan, D. (eds.): Neighbourhood Effects Research: New Perspectives. Dordrecht, 79-100.

Laska, S. B.; Spain, D. (eds.) (1980): Back to the City. Issues in Neighborhood Renovation. New York.

Lazarsfeld, P.; Berelson, B.; Gaudet, H. (1944): The People's Choice. How the Voter makes up his Mind in a Presidential Campaign. New York.

Lees, L.; Slater, T.; Wyly, E. (eds.) (2008): Gentrification. London, New York.

Lees, L.; Slater, T.; Wyly, E. (eds.) (2010): The Gentrification Reader. London, New York.

Lynn, P. (ed.) (2009): Methodology of Longitudinal Surveys. Chichester.

Ludwig, J.; Liebman, J. B.; Kling, J. R.; Duncan, G. J.; Katz, L. F.; Kessler, R. C.; Sanbonmatsu, L. (2008): What Can We Learn about Neighborhood Effects from the Moving to Opportunity Experiment? In: American Journal of Sociology 114, 1, 144-188.

Manley, D.; van Ham, M.; Doherty, J. (2012): Social Mixing as a Cure for Negative Neighbourhood Effects: Evidence-based Policy or Urban Myth? In: Bridge, G.; Butler, G.; Lees, L. (eds.): Mixed Communities. Gentrification by Stealth? Bristol, 151-167. 
Musterd, S.; Galster, G. C.; Andersson, R. (2012): Temporal dimensions and the measurement of neighbourhood effects. In: Environment and Planning A 44, 3, 605-627.

Myers, A. S. (2013): Secular Geographical Polarization in the American South: The Case of Texas, 1996-2010. In: Electoral Studies, $32,1,48-62$.

Orr, L.; Feins, J.; Jacob, R.; Beecroft, E.; Sanbonmatsu, L.; Katz, L. F.; Liebman, J.B.; Kling, J. R. (2003): Moving to Opportunity. Interim Impacts Evaluation. Washington.

Park, R.; Burgess E.; McKenzie, R. (1925): The City. Chicago, London.

Popkin, S. J.; Cunningham, M. K. (2009): Has HOPE VI Transformed Resident's Lives? In: Cisneros, H. G.; Engdahl, L. (eds.): From Despair to HOPE. HOPE VI and the New Promise of Public Housing in America's Cities. Washington, 191-203.

Sampson, R. J. (2012): Great American City. Chicago and the Enduring Neighborhood Effect. Chicago, London.

Schelling, T. C. (1971): Dynamic Models of Segregation. In: Journal of Mathematical Sociology 1, 1, 143-186.

Schelling, T. C. (1978): Micromotives and Macrobehavior. New York.
Skogan, W. G. (1990): Disorder and Decline. Crime and the Spiral of Decay in American Neighborhoods. Berkeley, New York, Toronto.

Smith, N.; Williams, P. (eds.) (1986): Gentrification of the City. Boston.

Spiess, M. (2005): Derivation of Design Weights: The Case of the German Socio-Economic Panel (SOEP). Berlin. = DIW Berlin Data Documentation, 8.

Stadt Köln (ed.) (2012): Statistisches Jahrbuch 2012, 90. Jahrgang (Statistical Yearbook 2012, Volume 90). Köln.

Theodorson, G. A. (ed.) (1961): Studies in Human Ecology. New York. Theodorson, G. A. (ed.) (1982): Urban Patterns. Studies in Human Ecology. Revised Edition. London.

Vermunt, J. (1996): Causal Log-Linear Modeling with Latent Variables and Missing Data. In: Engel, U.; Reinecke, J. (eds.): Analysis of Change: Advanced Techniques in Panel Data Analysis. Berlin, New York, 35-60.

Wasmer, M.; Scholz, E.; Blohm, M. (2010): Technical Reports 2010/4. Konzeption und Durchführung der "Allgemeinen Bevölkerungsumfrage der Sozialwissenschaften” (ALLBUS) 2008. Mannheim.

Wilson, W. J. (1987): The Truly Disadvantaged. Chicago, London. 